\title{
Squibs
}

\section{When silence may mean derision}

\author{
Varol Akman \\ Dept. of Computer Engineering and Information Science, Faculty of Engineering, Bilkent University, \\ Bilkent 06533, Ankara, Turkey
}

In a recent squib, Kurzon (1992) shows that silence does not necessarily mean lack of power: the silent response to a question may well be aiming at gaining control of a situation, viz. exercizing power. In the present squib I would like to extend Kurzon's analysis and argue (via two examples which display some close parallels to real-life incidents that I am familiar with) that at times silence may mean derision or ridicule.

The silence exhibited in my examples can be understood as a speech act of the form "I will not participate in order to show people (the listeners or in general, others present) that you are a laughingstock". Clearly, this is appreciably different from Kurzon's example where the silent addressee is saying in effect to the questioner that "You need me to give you the information you want. I am not cooperating with you, and you cannot make me".

\section{Example 1}

The setting is a country after a military coup. The leaders of the takeover declared that they did this in order to save the country and the constitution from terrorist attacks. A well-known columnist (X) who holds a Ph.D. in political science is being interrogated by a police chief $(\mathrm{Y})$ in Y's office in the presence of Y's aides. $\mathrm{X}$ is being accused of helping student activists in the country. At a particular point during the interrogation $\mathrm{Y}$ feels a need to lecture:

"You know what? These students got it all wrong! I also did a fair amount of reading about socialism when I was a student. And let me tell you my honest opinion about it. You've been to the United States many times, right? Don't you think that it is the U.S. which is a truly socialist country?"

At this point $\mathrm{Y}$ is expecting some kind of reaction from $\mathrm{X}$ regarding this claim. When $\mathrm{X}$ keeps silent, she communicates a disdain for $\mathrm{Y}$ and his views, silently conveying that his views are not worth a response. 


\section{Example 2}

Same setting. A famous professor of law (X) is being questioned in a military court. In the past he played a major role in the preparation of the constitution. $\mathrm{X}$ is now being accused of assisting the activities of a secret organization to destroy the nation's sovereignty. The judge $(\mathrm{Y})$ builds her case on the allegation that $\mathrm{X}$ has violated a specific constitutional provision. When $\mathrm{X}$ objects to this claim and tries to demonstrate why there is no basis for the allegation, $\mathrm{Y}$ explodes.

"What do you mean when you say that I'm misrepresenting or misreading the constitution. What makes you think that you know better?"

Surely X knows better! After all he was instrumental in drafting the entire constitution in its final form. $\mathrm{X}$, nonetheless, just keeps silent.

I would like to make a few observations about the situations in which silence may mean derision. In general, such circumstances are distinguished by the existence of an 'audience' in addition to a questioner and an addressee with a shared knowledge of the audience about the qualities of the addressee and the questioner (e.g., level of education, past accomplishments, integrity, etc.) which makes silence work as in the above examples. On this account, two individuals A and B (say two aides of Y in example 1) share the knowledge that $\mathrm{X}$ is an expert on political affairs. When this shared knowledge is absent, the silence seems to lack a negative force. Note also that there is no requirement for an immediate audience. For example, if $X$ is sure that the proceedings of the court hearing (cf. example 2) will be made public, then his silenceas-derision may be successful even when it is not 'performed' in front of an audience.

What if there is no audience? I believe that in this case a silent response conveys a message from the silent person of self-pity, of the sort "This is really tragic! Mine is really a miserable situation". It is quite clear (at least to me) that such a permanent dialogue with oneself should be given a psychological interpretation in the sociopragmatic model of Kurzon (1992, the figure on p. 93).

Stated in Austin's terms, this squib then shows that certain conditions have to be satisfied if a silent utterance is to be felicitous.

\section{Reference}

Kurzon, Dennis, 1992. When silence may mean power. Journal of Pragmatics 18: 92-95. 


\title{
The case of a broken cohesive chain
}

\author{
Dennis Kurzon \\ Department of English, Hebrew University, Mount Scopus, Jerusalem 91905, Israel
}

In the case of a non-fictional text, information usually flows from the known to the unknown as far as content is concerned. A writer or speaker will base new ideas on what is already known to the addressee. However, on the expression plane, in terms of NP reference, anaphora is the norm, that is to say information flows from unknown or indefinite NPs to definite NPs or pronouns. The unmarked, anaphoric, cohesive chain (to use Halliday and Hasan's (1976) term) may be illustrated as follows:

(1) A young girl [indefinite NP] walked into the lobby of the hotel. She [pronoun cohesive with 'a young girl'] was wearing a light summer dress.

The following, in reverse order, is, I believe, unacceptable:

(2) *She walked into the lobby of the hotel. A young girl was wearing a light summer dress.

In terms of anaphoric reference, then, we move from the unknown to the known. Indefinite expressions, once given in a text, become definite by virtue of the fact that they are no longer unknown. This textual feature, in the form of the unmarked cohesive chain, may be considered structural in essence; the shift from indefinite to definite is fairly automatic. Now, let us take another text, and work through the cohesive chains with respect to anaphoric reference. We shall take it paragraph by paragraph:

(3a) A girl aged 16 armed with a shotgun held up a class of children at a comprehensive school in Hampshire yesterday. A shot was fired into the ceiling as she was being overpowered by three police officers. ${ }^{1}$

Here, we would recognise without any trouble a newspaper report about a girl with a shotgun entering a school. She is first mentioned in the form of an indefinite NP, as expected ('A girl aged 16 ...'). Other entities in the report are at this stage also unknown, so they, too, are expressed as indefinite NPs (e.g. 'a class', 'a comprehensive school'). When the girl is mentioned for the second time, we find, again as expected, anaphoric reference to her through the pronoun 'she'. So far so good.

Let us continue with the second paragraph of the same report:

(3b) Police said that soon after school began at Amery Hill Secondary, Alton, the girl, armed with a single-barrelled shotgun belonging to her brother, went into one of the classrooms and threatened a teacher and about 30 pupils.

1 This newspaper report originated in the London Times, but is quoted in Spectrum, edited by Michael Swann (Cambridge University Press, 1980: 73), a book presenting material in varieties of English. 